\title{
A STUDY ON BENDING DEFORMATION BEHAVIOR OF NI-BASED DS AND SC SUPERALLOYS
}

\author{
H. Tamaki ${ }^{1}$, K. Fujita ${ }^{2}$, A. Okayama ${ }^{2}$, N. Matsuda ${ }^{3}$, A. Yoshinari $^{1}$ and K. Kakehi ${ }^{4}$ \\ ${ }^{1}$ Hitachi Research Lab., Hitachi, Ltd.; MD\#840 7-1-1 Ohmika, Hitachi, Ibaraki 319-1292, Japan \\ ${ }^{2}$ Hitachi Kyowa Engineering Co., Ltd.; 3-10-2 Benten, Hitachi, Ibaraki 317-0072, Japan \\ ${ }^{3}$ Hitachi Engineering Co., Ltd.; 3-2-1 Saiwai, Hitachi, Ibaraki 317-0073, Japan \\ ${ }^{4}$ Tokyo Metropolitan Institute of Technology; 6-6 Asahigaoka, Hino, Tokyo 191-0065, Japan
}

Keywords: Bending Creep, Directionally Solidified, Single Crystal, Gamma Prime Rafting, CM186LC, YH61

Introduction

\begin{abstract}
Bending deformation behavior of Ni-based directionally solidified (DS) and single crystal (SC) superalloys was studied. For a DS superalloy, bending creep curves at 800,850 and $900{ }^{\circ} \mathrm{C}$ were obtained. As a result, the stress exponents for the steady-state creep displacement rates of the bending creep were found to show the almost same values as those for the steady-state creep strain rates of the tensile creep. It was also confirmed that activation energy for the bending creep corresponded to that for the tensile creep within the temperature range of this study. It can be concluded from these results that the bending creep behavior of DS superalloys can be deduced from the simple tensile creep test data because the correspondence of the deformation mechanism between the bending and the tensile creep was proven.

For a SC superalloy, notable secondary orientation dependence of the steady-state creep displacement rates was observed at $750^{\circ} \mathrm{C} / 950 \mathrm{MPa}$. The specimen, whose slip system caused the $45^{\circ}$ shear-type slip, exhibited apparently faster creep displacement rate than the specimen, whose slip system caused the hinge-type deformation, even if their tensile/compressive directions were same. At $982^{\circ} \mathrm{C} / 294 \mathrm{MPa}$, secondary orientation dependence of the creep displacement rates was not significant while [011] specimens showed higher creep resistance than [001] specimens. The microstructural observations after bending creep tests provided interesting results that one type of raft-like microstructure observed in the tension side of [011] specimens was also found in the compression side of [001] specimens and another type of raft-like microstructure observed in the compression side of the [011] specimens was also found in the tension side of the [001] specimens.
\end{abstract}

Uniaxial tensile deformations such as creep have been extensively characterized for Ni-based directionally solidified (DS) and single crystal (SC) superalloys. However, only few studies [1] [2] have been reported concerning bending deformation behavior of Nibased DS and SC superalloys. It can be considered as very important to characterize bending deformation behavior of $\mathrm{Ni}$ based superalloys used for gas turbine components because bending stresses are often observed in some critical portions of gas turbine blades and vanes. The representative example is the tip shroud [3]. The longer blades tend to be equipped with the tip shroud in order to effectively reduce gas leakage and increase high cycle fatigue margin on fundamental modes such as $1^{\text {st }}$ bending. The overhanging of the shroud causes a relatively high bending stress at the fillet which has become to be exposed to more severe circumstances due to the increase in gas-firing temperature of modern gas turbines. For reasons mentioned above, precise investigations of bending deformation behavior of Ni-based DS and SC superalloys have been required.

\section{Experimental}

A commercial $2^{\text {nd }}$ generation DS superalloy CM186LC ${ }^{\circledR}[4]$ was used to investigate bending deformation behavior of a DS superalloy while a low angle grain boundary resistant SC superalloy YH61 [5] was used to examine that of a SC superalloy. The nominal compositions of these alloys are listed in Table 1 and the heat treatment conditions used in this study for each alloy are shown in Figure 1.

Table 1 Nominal Compositions of CM186LC and YH61, wt $\%$

(Ni: Balance)

\begin{tabular}{cccccccccccccc} 
alloy & Cr & Co & W & Re & Mo & Ta & Nb & Ti & Al & Hf & Zr & C & B \\
\hline CM186LC & 6 & 9 & 8 & 3 & 0.5 & 3 & - & 0.7 & 5.7 & 1.4 & 0.005 & 0.07 & 0.015 \\
YH61 & 7 & 1 & 8.8 & 1.4 & 0.9 & 8.8 & 0.8 & - & 5 & 0.25 & - & 0.07 & 0.02
\end{tabular}




\section{CM186LC}

Aging

\section{$1080^{\circ} \mathrm{C} / 4 \mathrm{~h}$}

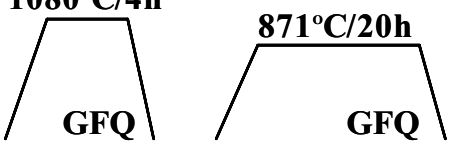

YH61

\section{Solution Heat Treatment Final step: $1280^{\circ} \mathrm{C} / 4 \mathrm{~h}$}
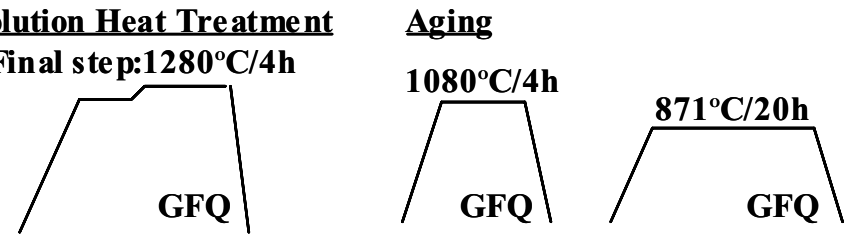

Figure 1 Heat treatment conditions used in this study for CM186LC and YH61

Apparatus for the bending test and the loading configuration are described in Figures 2 and 3, respectively. Four point bending tests were performed by using a tensile creep machine installed a bending device machined from a YH61 DS bar. The rods machined from a YH61 SC casting were used for the load-points and the load-point displacements $\Delta_{\mathrm{p}}$ were continuously monitored until apparent steady-state creep was observed. There is stress gradient in the specimen during the bending test and the upper and lower main surfaces are subjected to the maximum-compressive and the maximum-tensile uniaxial-stresses, respectively, while stress of the central plane, which corresponds to the neutral plane, is zero. Moreover, the stress redistribution may occur by the stress gradient. Therefore, unless otherwise specified, the stress of bending creep test conditions is represented by the initial stress (elastic stress) $\sigma_{\mathrm{e}}$ on the lower main surface.

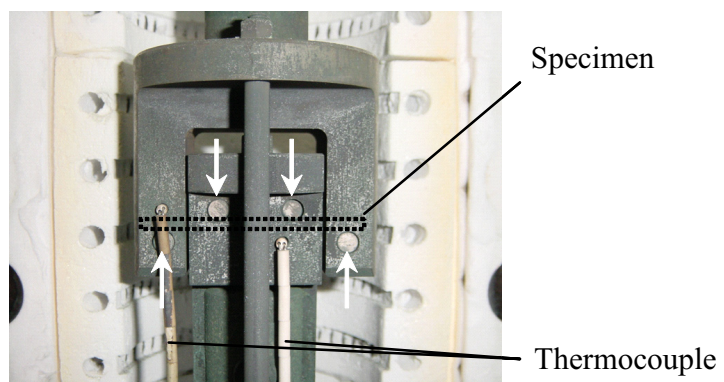

Figure 2 Apparatus for the bending test

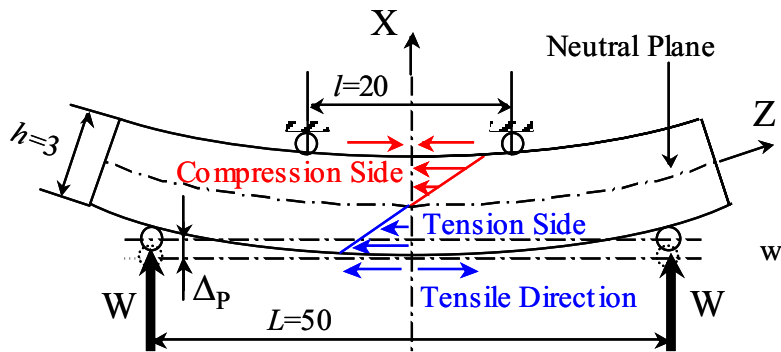

Figure 3 Loading configuration in this study ( $\mathrm{mm})$

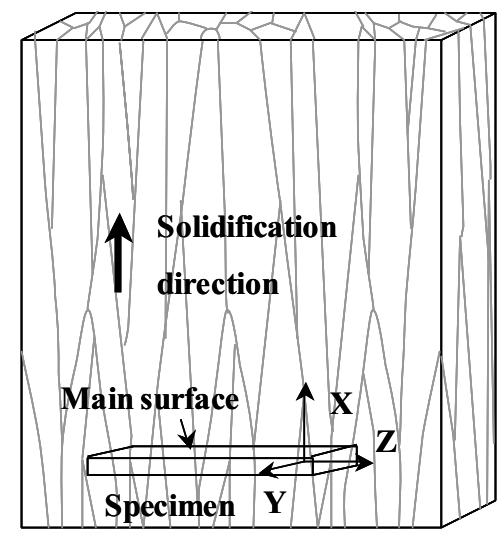

Figure 4 Relationship between the alignment of a specimen and solidification direction of a DS slab

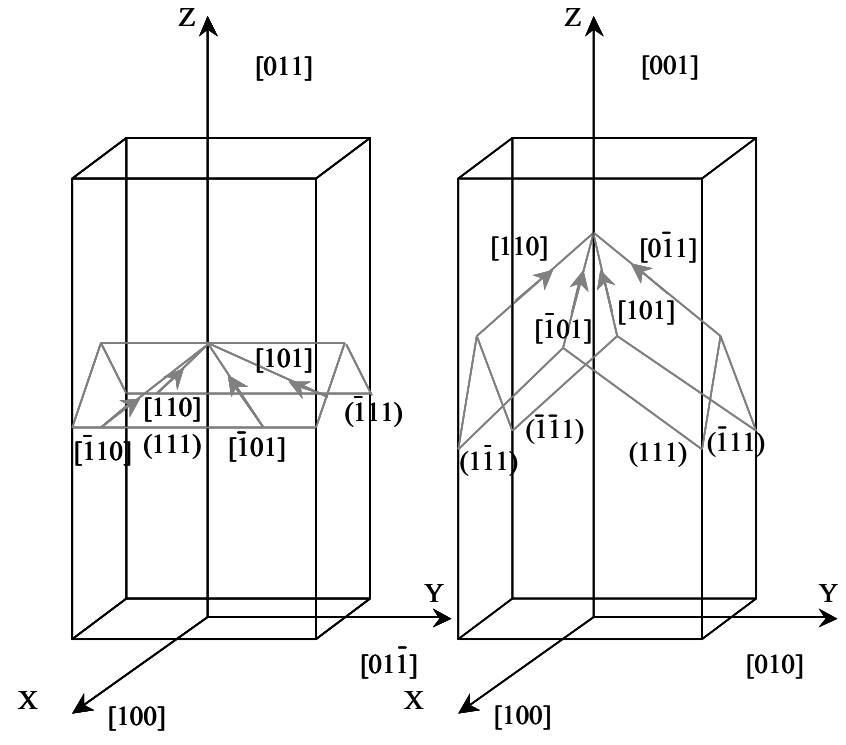

(a) Specimen A

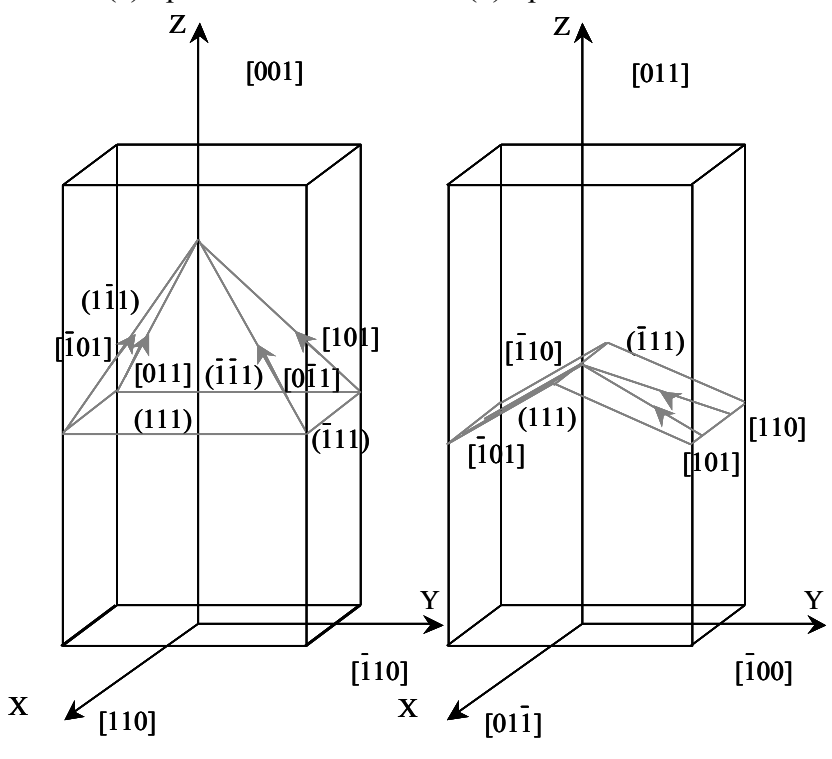

(c) Specimen C

(d) Specimen D

Figure 5 Crystallographic orientations for four kinds of YH61 SC specimens 
The shape of the standard test specimens was a plate whose dimension was $60 \mathrm{~mm}$ length $\mathrm{x} 10 \mathrm{~mm}$ width $\mathrm{x} 3 \mathrm{~mm}$ height. The standard DS specimens were machined from DS slabs in order to align the longitudinal direction parallel to the DS-transverse direction and the main surface perpendicular to the DS growth direction as shown in Figure 4. Four kinds of SC specimens were prepared to examine the effects of primary (longitudinal direction of the specimen) and secondary (transverse direction of the specimen) orientations on the steady-state creep displacement rate The crystallographic orientations for these plates are described in Figure 5. For DS specimens, their relationship between the crystallographic alignment and direction of the external force (centrifugal force) corresponds to the relationship observed in the shroud fillet of actual DS blades. In the case of four kinds of SC specimens, the specimens $\mathrm{A}$ and $\mathrm{B}$ are probable configuration in the shroud fillet of actual SC blades. Although specimens $\mathrm{C}$ and $\mathrm{D}$ are not possible crystallographic alignment in the shroud fillet of actual SC blades, they were studied for the purpose of examining the bending deformation phenomena of representative crystallographic orientations of Ni-based SC superalloys. Moreover, complicated thermal stress may cause bending deformation of these crystallographic alignments at some portions. Bending creep tests were performed at temperature range between 750 and $982^{\circ} \mathrm{C}$ and stress $\left(\sigma_{\mathrm{e}}\right)$ range between 294 and $950 \mathrm{MPa}$. The load-point displacements $\Delta_{\mathrm{p}}$ were continuously monitored until the steady-state creep rates were clearly determined and then tests were terminated before the accelerated creep or the rupture were observed.

\section{Results and Discussion}

\section{Bending creep of DS specimens}

Figure 6 shows typical bending creep curves for CM186LC DStransverse direction at 800,850 and $900^{\circ} \mathrm{C}$. It is well known that the steady-state creep behavior can be described by Norton's law in a form $\dot{\varepsilon}_{\mathrm{c}}=A \cdot \sigma^{\mathrm{n}}$, where $\dot{\varepsilon}_{\mathrm{c}}$ is steady-state creep strain rate, $\sigma$ is applied stress, $\mathrm{A}$ and $\mathrm{n}$ are experimental coefficients. For the tensile creep behavior of Ni-based superalloys, extensive studies have been carried out to determine the power-law creep parameters because they are necessary to predict the high temperature component life precisely. In this study, the powerlaw creep parameters for the bending creep of a Ni-based DS superalloy were examined in order to establish the lifetime prediction method concerning the bending creep behavior of DS superalloys. Chuang [6] studied how to estimate the power-law creep parameters for tensile and compressive creep of ceramic materials from four point bending creep test data. Assuming that the parameters $\mathrm{A}$ and $\mathrm{n}$ for the objective material show almost same values, respectively, in both compression and tension sides, the paper shows that the steady-state creep strain rate for the lower main surface $\dot{\varepsilon}_{\mathrm{bc}}$ can be calculated from the steady-state creep displacement rate $\dot{\Delta}_{\mathrm{p}}$ by the following equation:

$$
\dot{\varepsilon}_{\mathrm{bc}}=\{2(n+2) h\} /[(L-l)\{L+(n+1) l\}] \dot{\Delta}_{\mathrm{p}}---(1)
$$

and the stress on the lower main surface after the stress redistribution $\sigma_{\mathrm{s}}$ can be described by

$$
\sigma_{\mathrm{s}}=\sigma_{\mathrm{e}}(2 n+1) / 3 n---(2)
$$

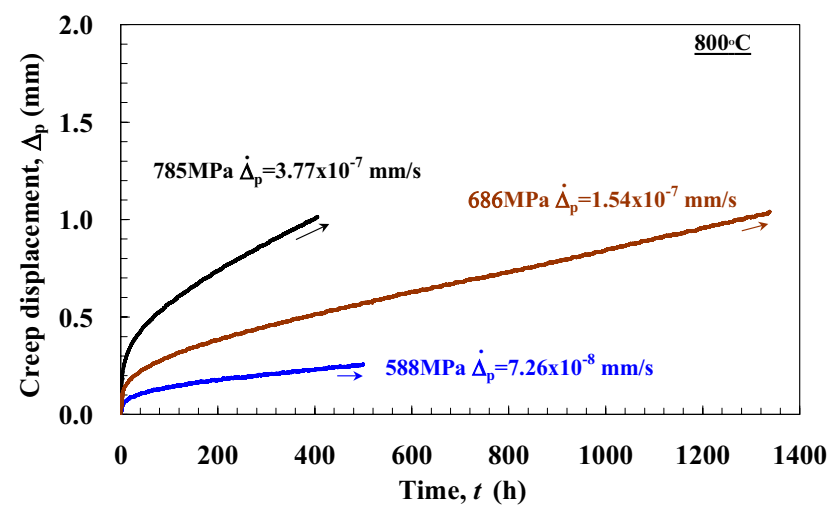

(a) $800^{\circ} \mathrm{C}$

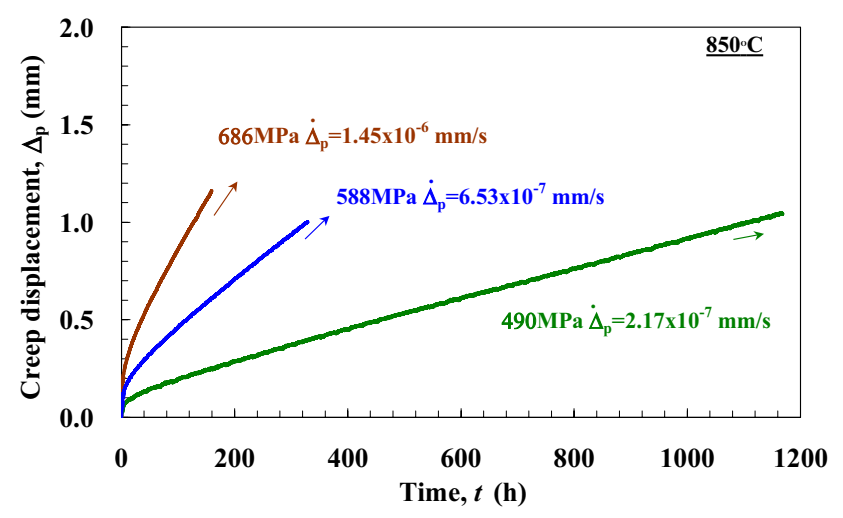

(b) $850^{\circ} \mathrm{C}$

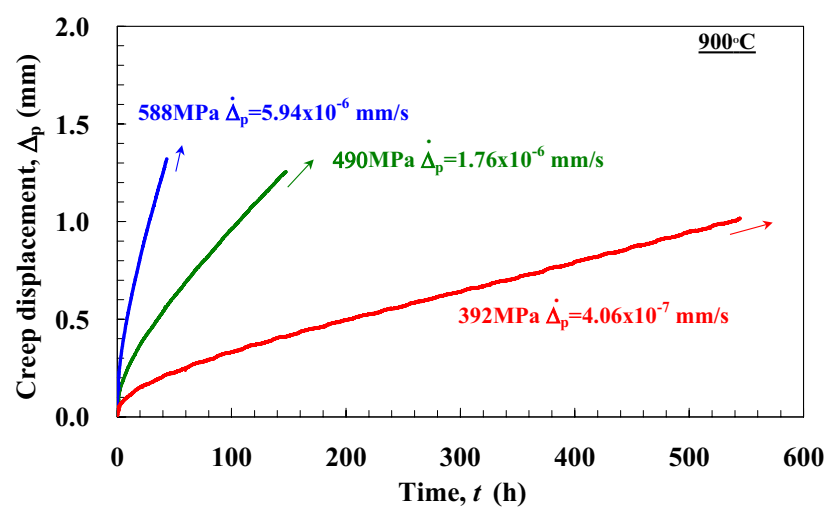

(c) $900^{\circ} \mathrm{C}$

Figure 6 Bending creep curves for CM186LC DS-transverse direction at 800,850 and $900^{\circ} \mathrm{C}$

where $\mathrm{h}$ is the height of the specimen, $\mathrm{L}$ is major and $l$ is minor spans, respectively. On the lower main surface, the following equation stands up:

$$
\dot{\varepsilon}_{\mathrm{bc}}=A \cdot \sigma_{\mathrm{s}}^{\mathrm{n}}---(3)
$$

From the above equations, relationship between the steady-state creep displacement rate $\dot{\Delta}_{\mathrm{p}}$ and the initial stress $\sigma_{\mathrm{e}}$ can be described by the following equation: 


$$
\dot{\Delta}_{\mathrm{p}}=[(L-l) \cdot\{L+(n+1) l\}] /\{2(n+2) h\} \cdot A \cdot\left[\sigma_{\mathrm{e}}\{(2 n+1) / 3 n\}\right]^{\mathrm{n}}---(4)
$$

where $\mathrm{L}, l$ and $\mathrm{h}$ are constant in this study, therefore the equation (4) can be modified to a more simple form:

$$
\dot{\Delta}_{\mathrm{p}}=A^{\prime} \cdot \sigma_{\mathrm{e}}{ }^{\mathrm{n}}---(5)
$$

Figure 7 shows relationship between $\dot{\Delta}_{\mathrm{p}}$ and $\sigma_{\mathrm{e}}$ at 800, 850 and $900^{\circ} \mathrm{C}$ compared with relationship between $\dot{\varepsilon}_{\mathrm{c}}$ and $\sigma$ for tensile creep tests. In this comparison, the tensile/compressive direction for the bending creep and the tensile direction for the tensile creep were the same direction (DS-transverse). It is found from Figure 7 that stress exponents for the bending creep and the tensile creep exhibited the almost same value, about 7 , at $900^{\circ} \mathrm{C}$ while the exponent for the bending creep was slightly lower than that for the tensile creep at $850^{\circ} \mathrm{C}$. The linear relationship observed in Figure 7 (a) confirms that the equation (5) can be useful to predict the bending creep behavior for the alloy when temperature and applied stress are known.

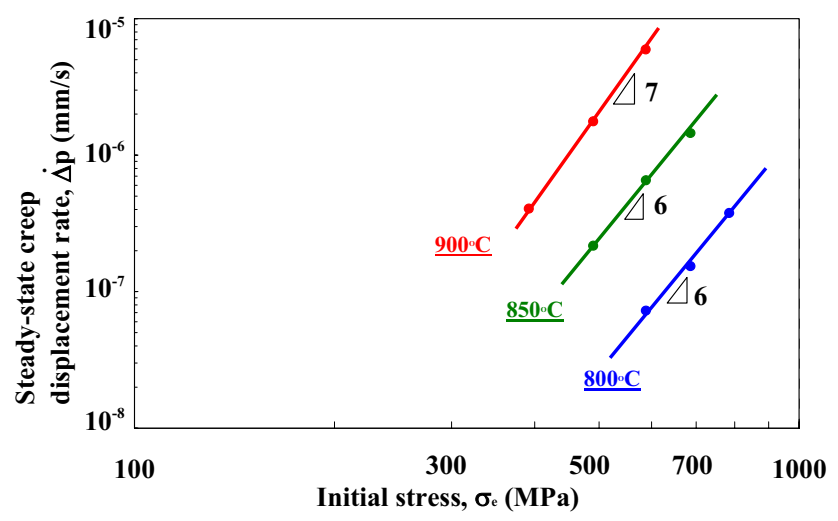

(a) Bending creep

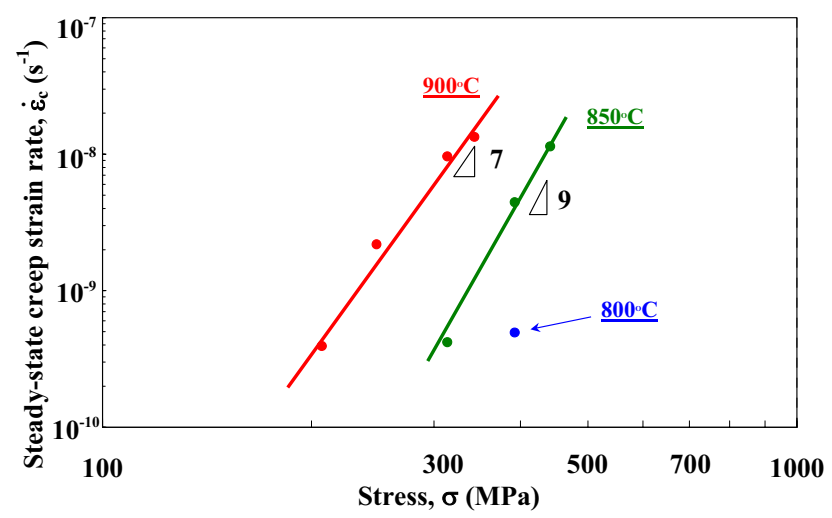

(b) Tensile creep

Figure 7 Power-law bending creep parameters for bending creep tests compared with power-law creep parameters for tensile creep tests (CM186LC DS-transverse direction)

More extensive investigation was carried out about comparison of deformation mechanism between the bending and the tensile creep. By using the stress exponent determined in Figure 7(a), the power-law creep parameters of the equation (3) for the bending creep at $900^{\circ} \mathrm{C}$ were calculated. The result is described in Figure 8 compared with those obtained from tensile creep tests. It is found from Figure 8 that the steady-state creep strain rates for the lower main surface of the bending creep tests were quite similar to those for the tensile creep tests and also the stress exponents for both the bending and the tensile creep tests were almost of same value, about 7 , while a small difference was observed for the $A$ value. Whereas Chuang [6] concluded the above equations cannot apply to the calculation for the parameters of ceramic materials due to their tension/compression asymmetry of the parameters, the correspondence of the parameters between the bending and the tension in CM186LC DS indicates that the tension/compression asymmetry for CM186LC DS at $900^{\circ} \mathrm{C}$ is almost negligible and therefore the equations can apply to the calculation for the powerlaw creep parameters of the bending creep after the slight modification.

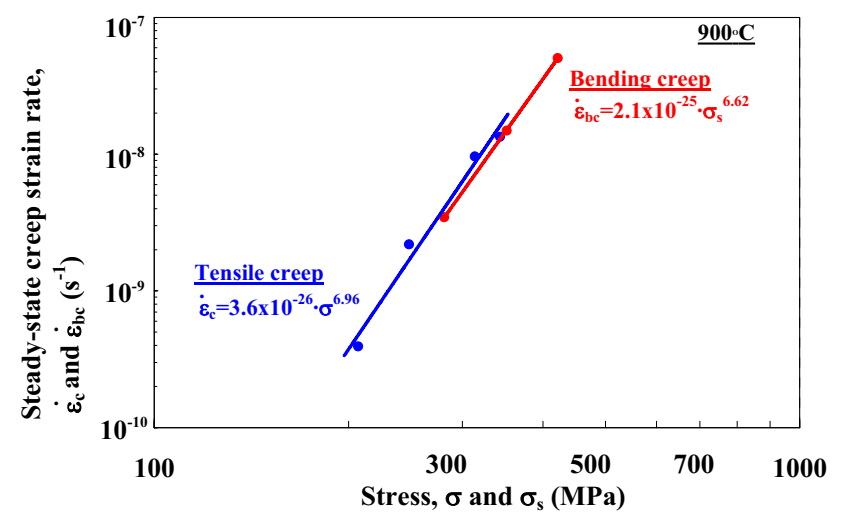

Figure 8 Power-law creep parameters for the lower main surface of bending creep tests compared with those for tensile creep tests(CM186LC DS-transverse direction)

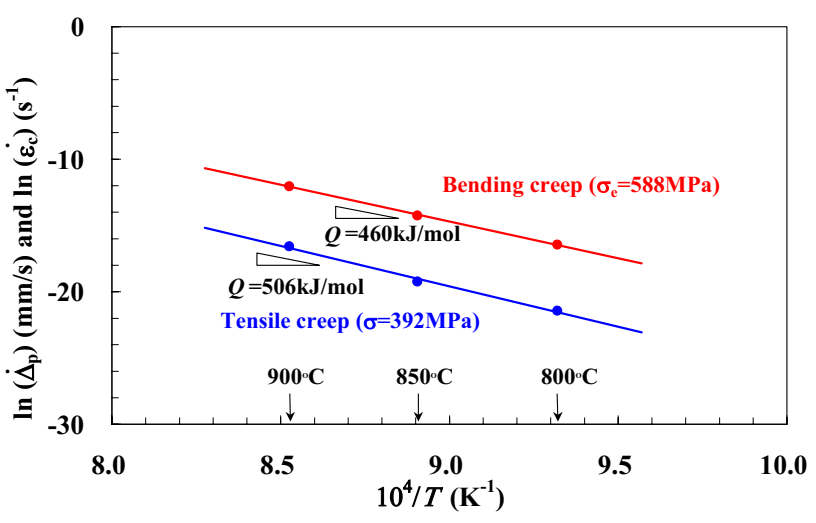

Figure 9 Arrhenius plots for steady-state creep displacement rates $\left(\dot{\Delta}_{\mathrm{p}}\right)$ of the bending creep and steady-state creep strain rates $\left(\dot{\varepsilon}_{\mathrm{c}}\right)$ of the tensile creep (CM186LC DS-transverse direction)

Activation energies for the bending and the tensile creep were also examined. Figure 9 shows arrhenius plots for steady-state creep displacement rates of the bending creep and steady-state creep strain rates of the tensile creep. Linear relationships were observed between $\ln \left(\dot{\Delta}_{\mathrm{p}}\right)$ and $1 / \mathrm{T}$ as well as $\ln \left(\dot{\varepsilon}_{\mathrm{c}}\right)$ and $1 / \mathrm{T}$. Activation energy for the tensile creep was $506 \mathrm{~kJ} / \mathrm{mol}$ which almost equivalents to that for Mar M200 (557kJ/mol [7] and $628 \mathrm{~kJ} / \mathrm{mol}$ [8]) and CMSX-3 (495kJ/mol [9]). They are generally accepted values for higher $\gamma^{\prime}$ containing superalloys, although 
they are considerably large in comparison with that for selfdiffusion in nickel, about $270 \mathrm{~kJ} / \mathrm{mol}$. Activation energy for the bending creep was $460 \mathrm{~kJ} / \mathrm{mol}$ which can be considered as equivalent to that for the tensile creep. This result indicates that creep deformations of the bending and the tensile are performed by the same deformation mechanism when the tensile/compressive direction for the bending creep is same as the tensile direction for the tensile creep and the test temperature range was between 800 and $900^{\circ} \mathrm{C}$.

It can be concluded from these results that the bending creep behavior of the CM186LC DS-transverse direction can be deduced from the simple tensile creep test data because the correspondences of the power-law creep parameters and the activation energy between the bending and the tensile creep were proven. However, as mentioned above, it should be noted that this method might be invalid when the tension/compression asymmetry for the power-low creep parameters is significant. The tension/compression asymmetry could be reduced by the increase in multiplicity of slip systems. Although the temperature range that CM186LC shows the tension/compression symmetry is not certain, the temperature to which the shroud fillet is exposed can be considered as sufficiently higher than the temperature that can allow the multiplicity of slip systems to increase for CM186LC. Therefore, the data obtained and the equations demonstrated in this study could be applied to estimate the deformation of shrouded DS blades. The reason why Chuang [6] observed significant tension/compression asymmetry for ceramic materials can be considered that the test temperature $1100^{\circ} \mathrm{C}$ would be lower than the temperature that can allow the multiplicity of slip systems to increase for ceramic materials.

It should also be noted that $A$ ' in the equation (5) depends on $L, l$ and $h$. In order to confirm the universality of the equation (5), the effect of specimen height on the load-point displacement $\Delta_{\mathrm{p}}$ was examined (Figure 10). Unlike the tensile creep, in the case of the bending creep, $\dot{\Delta}_{\mathrm{p}}$ is varied depending on the specimen height even if $\sigma_{\mathrm{e}}$ is same value. However unknown $\dot{\Delta}_{\mathrm{p}}$ for a certain specimen height can be easily calculated from already known $\dot{\Delta}_{\mathrm{p}}$ for another specimen height by considering the ratio of their specimen heights. It is found from Figure 10 that the calculated curves for specimen heights of 4 and $5 \mathrm{~mm}$ from $3 \mathrm{~mm}$ data show good agreement with the actual experimental data. This result makes it clear that the data obtained and the equations demonstrated in this study can be applied to other specimen shapes and other span lengths.

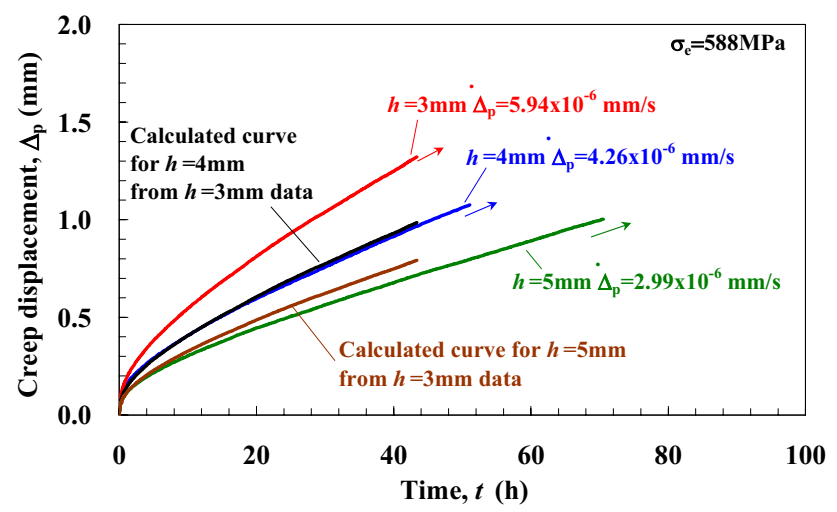

Figure 10 The effect of specimen height on the load-point displacement

\section{Bending creep of $\mathrm{SC}$ specimens}

The notable secondary orientation (transverse direction of the specimen) dependence of the steady-state creep displacement rates was observed in the bending creep tests of YH61 SC specimens. Figure 11 shows bending creep curves at $750^{\circ} \mathrm{C} / 950 \mathrm{MPa}$ for the four kinds of specimens with different crystallographic arrangements shown in Figure 5. Although the specimens $\mathrm{A}$ and $\mathrm{D}$ have the same tensile/compressive direction of [011], which corresponds to the longitudinal direction of the specimens, the steady-state creep displacement rate for the specimen A was apparently faster than that for the orientation D. In the case of tensile/compressive direction of [001], the specimen $\mathrm{B}$ also showed apparently faster creep rate than the specimen $\mathrm{C}$. It should be noted that the secondary orientation dependence of the steady-state ercreep strain rate cannot be observed in the normal tensile creep tests when round bar specimens are used. The different arrangements of the slip system in these four kinds of specimens can be considered to cause this significant secondary orientation dependence of the deformation in the case of bending creep tests. The arrangements are illustrated in Figure 5 by assuming that the $\{111\}<101>$ slip system could operate.

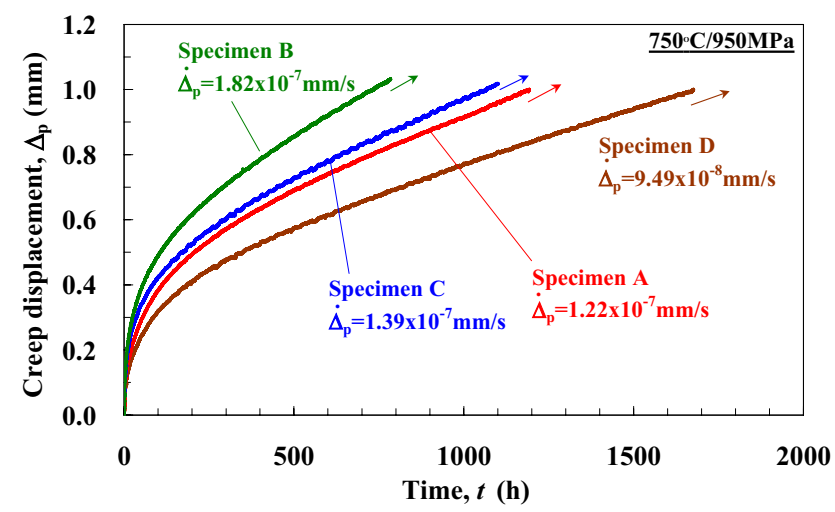

Figure 11 Bending creep curves at $750^{\circ} \mathrm{C} / 950 \mathrm{MPa}$ for the four kinds of YH61 specimens with different crystallographic arrangements shown in Figure 5

Figure 12 shows slip trace lines on the lower main surface observed for these specimens. Please note that the observations were performed to the specimens after the bending test at room temperature in order to avoid oxidation. It can be thought that same slip system could operate in both the bending test at room temperature and the bending creep test at $750^{\circ} \mathrm{C}$. It is found from Figure 12 that slip trace lines corresponding to $\overrightarrow{(111)}$ plane was only observed for the specimen A while those corresponding to $(111)$ and $(\overline{111})$ were observed for the specimen $D$. It can be considered from these observations that the $45^{\circ}$-shear-type slip operated in the specimen A whereas the hinge-type slip operated in the specimen D depending on their different arrangements of the slip system. As Kakehi pointed out [10], the hinge-type deformation requires contraction of the transverse direction in the tension side of the specimen, while it also requires expansion of the transverse direction in the compression side of the specimen, therefore this type of deformation could be constrained. However, the $45^{\circ}$-shear-type slip could not be constrained. This plastic anisotropy peculiar to the SC plate can be considered to cause the difference of creep rates between the specimens A and D while their tensile/compressive directions are the same. 


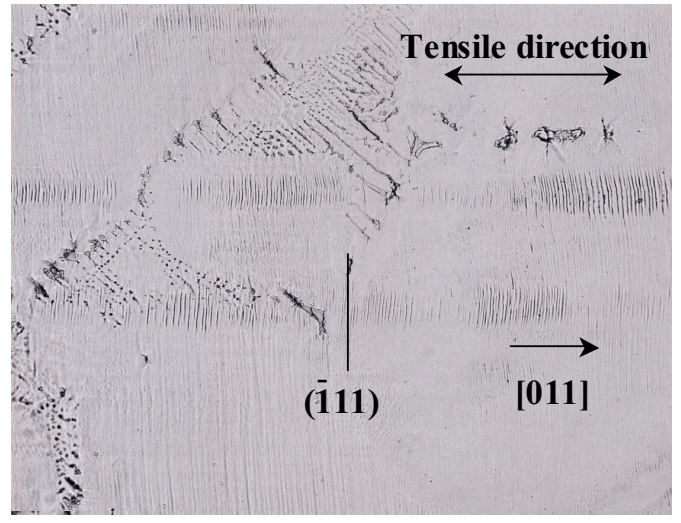

(a) Specimen A

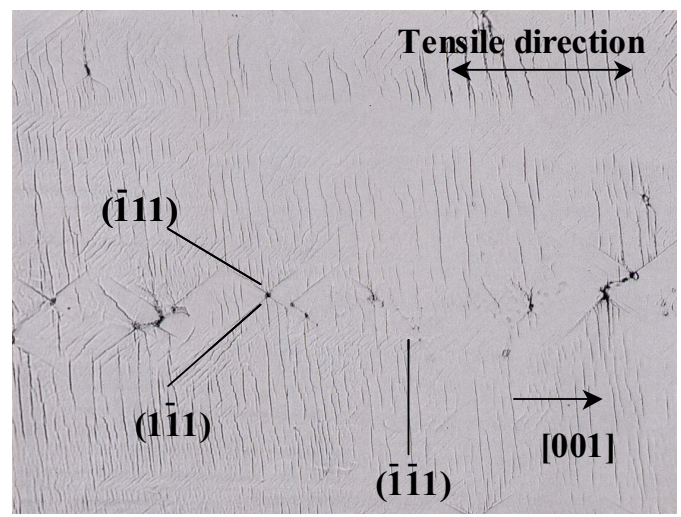

(c) Specimen C

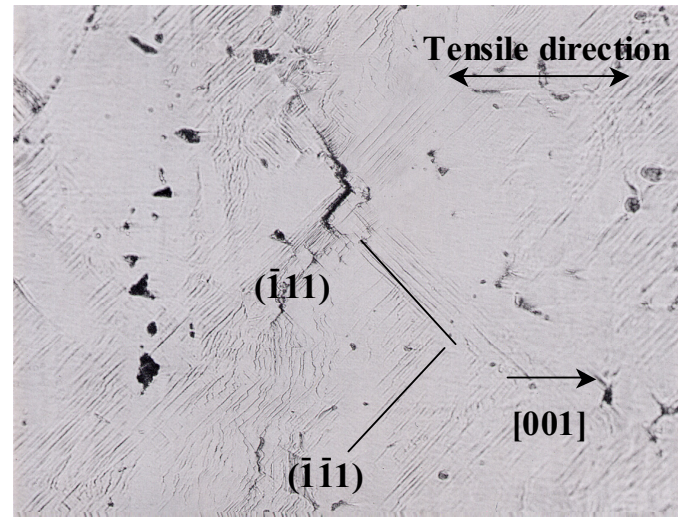

(b) Specimen B

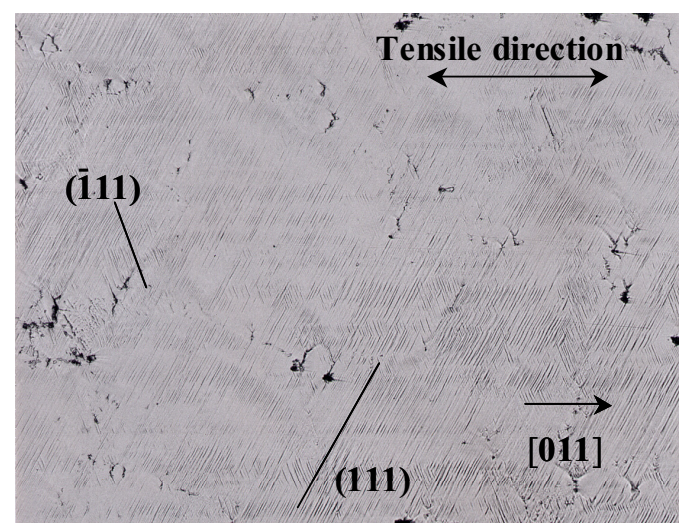

(D) Specimen D $\mathbf{5 0 \mu \mathrm { m }}$

Figure 12 Slip trace lines on the lower main surface for the four kinds of YH61 specimens after bending tests at room temperature

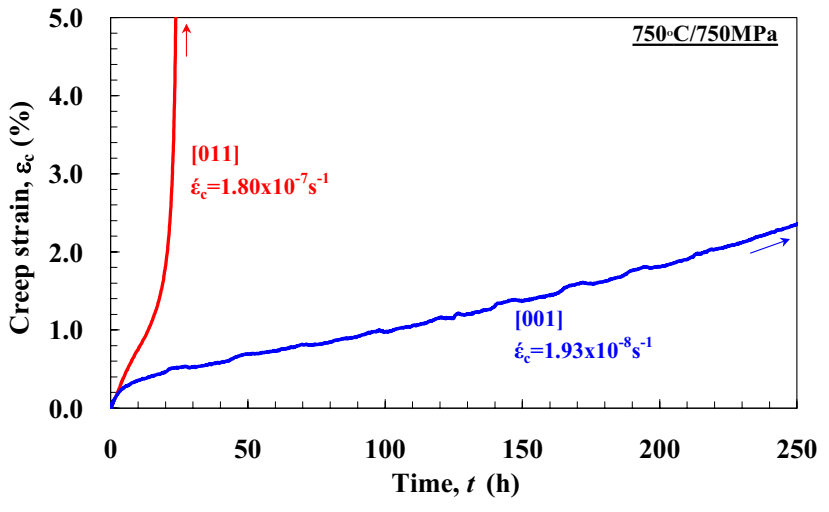

Figure 13 Tensile creep curves at $750^{\circ} \mathrm{C} / 750 \mathrm{MPa}$ for the [001] and [011] specimens of YH61

In the comparison between the specimens $\mathrm{B}$ and $\mathrm{C}, \overline{(111)}$ and (111) planes were observed for the specimen B while (111), $(\overline{111})$ and (111) were observed for the specimen $C$. In the case of the specimen $C$, it could be expected that the slip system on $(111)$ is the only operative slip system because the slip system on $\overrightarrow{(111)}$ could not be constrained while the slip system on $(\overrightarrow{111})$ and (111) could be constrained for the reasons mentioned above. However, operation of the slip system on $(\overline{1} 11)$ and $(1 \overline{1} 1)$ was also observed for the specimen $\mathrm{C}$. The evidence for the operation of the constrained slip system can be considered as one of the possible reasons why the specimen $\mathrm{C}$ showed higher bending creep resistance than that shown by the specimen $\mathrm{B}$. This result also agrees with investigation reported by Kakehi [11]. The investigation shows the specimen corresponding to the specimen $\mathrm{C}$ of this study exhibits higher tensile strength than the specimen corresponding to the specimen B of this study in the notched tensile test at $700^{\circ} \mathrm{C}$.

Figure 13 shows tensile creep curves for [001] and [011] specimens at $750^{\circ} \mathrm{C} / 750 \mathrm{MPa}$. It should be noted that the specimens $\mathrm{A}$ and $\mathrm{D}$, whose tensile/compressive directions were [011], exhibited lower creep rate than the specimens B and C, whose tensile/compressive directions were [001], in the bending creep tests whereas the [011] specimen showed about 10 times faster creep strain rate than the [001] specimen in the tensile creep tests. For the specimen D, its higher creep resistance can be explained by the hinge-type deformation, as already mentioned. However the specimen A, which showed the $45^{\circ}$-shear-type slip, also exhibited higher creep resistance than the [001] specimens. This result indicates that tension/compression asymmetry is significant for $\mathrm{YH} 61$ at $750^{\circ} \mathrm{C}$; therefore, higher compressive creep resistance of YH61 [011] may cause higher bending creep resistance of [011] specimens at $750^{\circ} \mathrm{C}$ although the [011] specimen showed lower tensile creep resistance at $750^{\circ} \mathrm{C}$. 


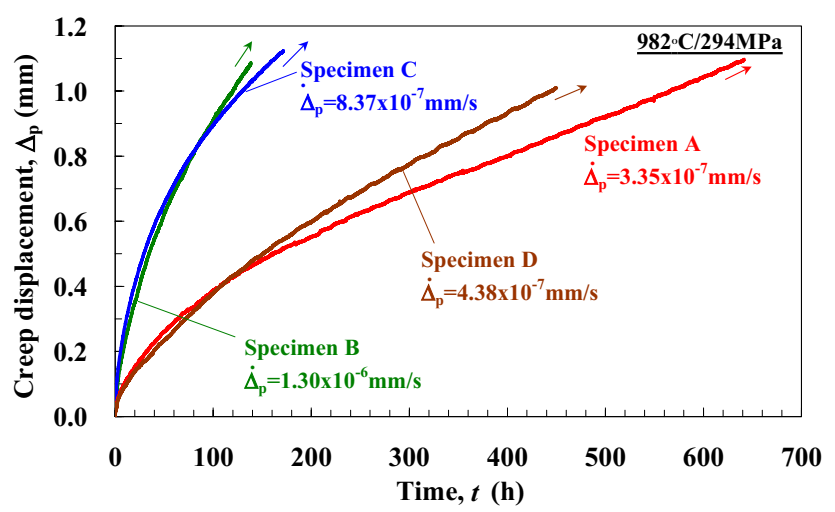

Figure 14 Bending creep curves at $982^{\circ} \mathrm{C} / 294 \mathrm{MPa}$ for the four kinds of YH61 specimens with different crystallographic arrangements shown in Figure 5

Figure 14 shows bending creep curves at $982^{\circ} \mathrm{C} / 294 \mathrm{MPa}$. In this condition, the specimens, whose tensile/compressive direction was [001], exhibited faster creep rate than the [011] specimens, and no significant secondary orientation dependence of the steady-state creep displacement rates was observed because the creep rates for the specimens $\mathrm{A}$ and $\mathrm{B}$ were almost equivalent to those of the specimens $\mathrm{D}$ and $\mathrm{C}$, respectively. The reason why no significant secondary orientation dependence of the deformation was observed at $982^{\circ} \mathrm{C}$ can be explained by the increased multiplicity of slip systems. It is generally accepted that the degree of plastic anisotropy is reduced at temperature above about $900^{\circ} \mathrm{C}$ due to operation of the $\{100\}<110>$ slip in addition to the $\{111\}<101>$ slip, especially for lower Mo content superalloys [12], although significant plastic anisotropy tends to be observed at $750^{\circ} \mathrm{C}$. Assuming the operation of the $\{100\}<110>$ slip, the hinge-type slip caused by the $\{111\}<101>$ slip can be replaced by the $45^{\circ}$-shear-type slip caused by $\{100\}<110>$ slip which could not be constrained. Therefore, the specimens A and D could exhibit almost same creep rates in this condition.

Figure 15 shows tensile creep curves for [001] and [011] specimens at $982^{\circ} \mathrm{C} / 206 \mathrm{MPa}$. For the tensile creep tests, creep resistance of the [011] specimen was higher than that of the [001] specimen at this temperature although shorter creep-rupture life was observed for the [011] specimen. Assuming the reduced tension/compression asymmetry for YH61 due to the increased multiplicity of slip systems at $982^{\circ} \mathrm{C}$, it can be considered from the above results that essentially higher creep resistance for [011] caused higher bending creep resistance of [011] specimens although the [011] specimen exhibited lower tensile creep resistance at $750^{\circ} \mathrm{C}$.

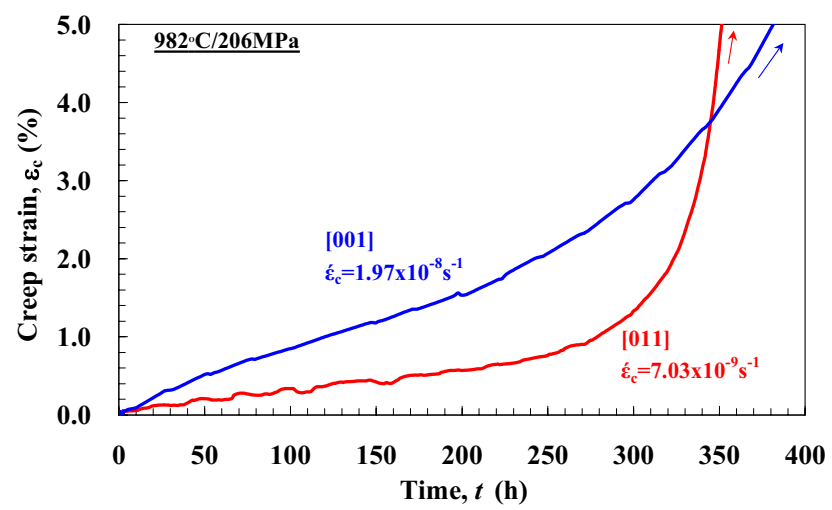

Figure 15 Tensile creep curves at $982^{\circ} \mathrm{C} / 206 \mathrm{MPa}$ for the [001] and [011] specimens of YH61

The evolution of microstructure such as raft-like microstructure in SC superalloys is one of the major concerns in this field. Although Ignat et al. [2] already showed the microstructural evolution of the bending crept specimen whose orientation corresponds to the specimen $\mathrm{C}$ of this study, morphological changes of $\gamma$ ' phases were investigated for these four kind of specimens after the $982^{\circ} \mathrm{C} / 294 \mathrm{MPa}$ tests. Secondary electron images and corresponding schematic representations of the $\gamma^{\prime}$ morphology are described in Figure 16. In the case of the specimen A whose tensile/compressive direction was [011], two types of plates, which were normal to [001] and [010], respectively, were observed in the tension side. Their coalescence was observed on two $\{100\}$ planes parallel to the stress axis and also two opposite $\{100\}$ planes, which were spaced at angle of $45^{\circ}$ to the stress axis. As expected, $\gamma$ ' phases remained cuboidal shape near the neutral plane because both tensile and compressive stresses were equal to zero on the neutral plane. In the compression side, one type of well-elongated $\gamma^{\prime}$ plates were observed. They were normal to [100] and their growth direction was parallel to the stress axis. It is perpendicular to raft-like microstructures often observed in the [001] tensile creep tests.

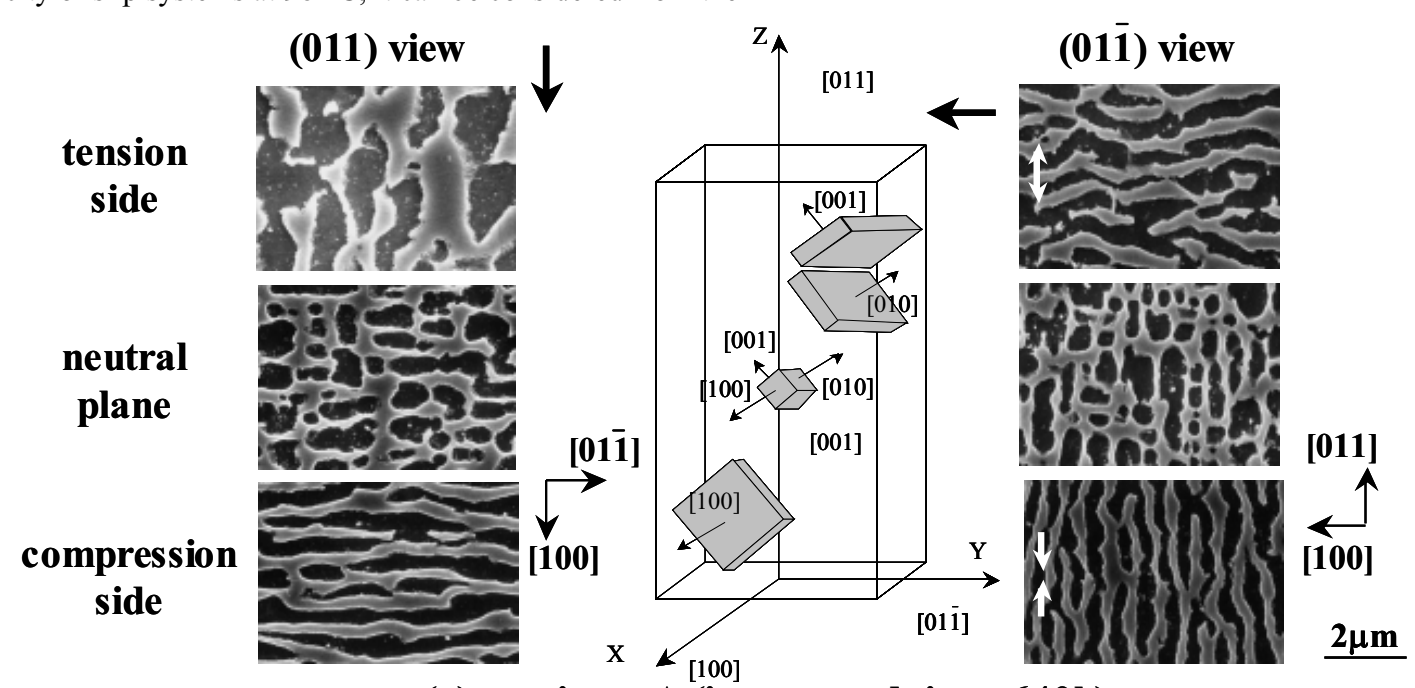

(a) specimen $A$ (interrupted time: 640h) 


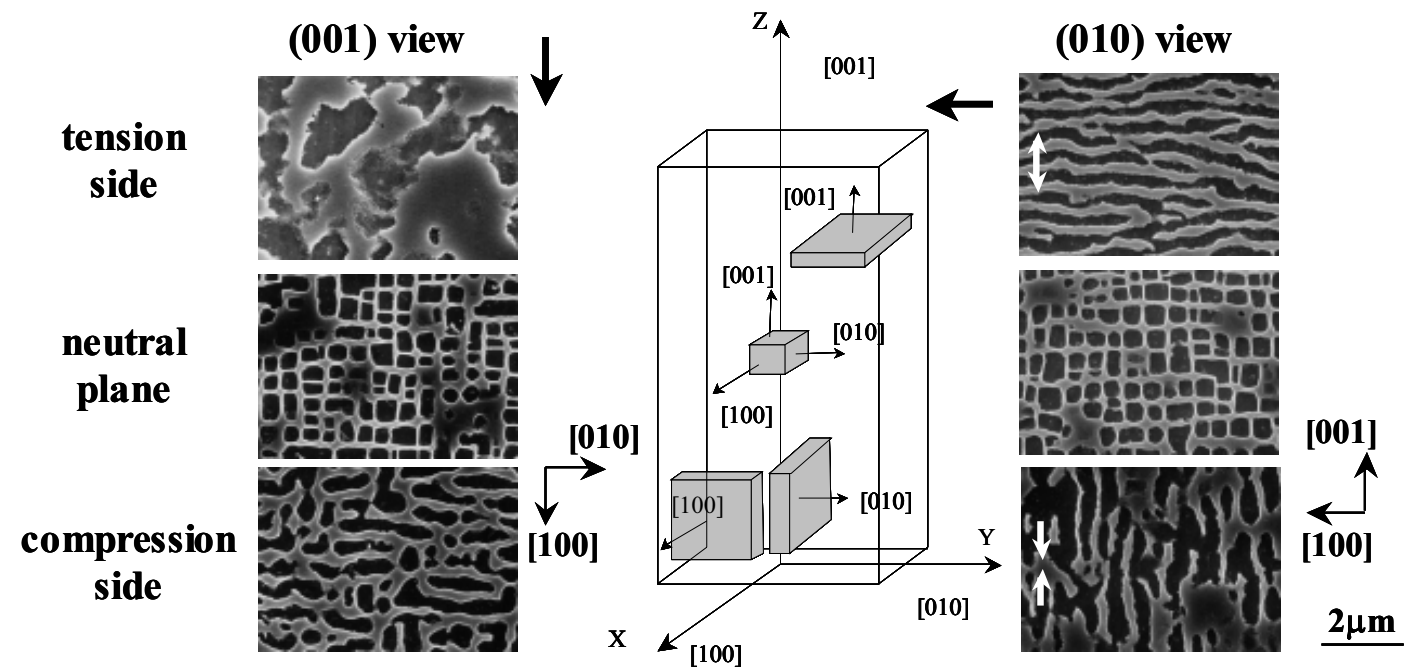

(b) specimen $B$ (interrupted time: $135 \mathrm{~h}$ )

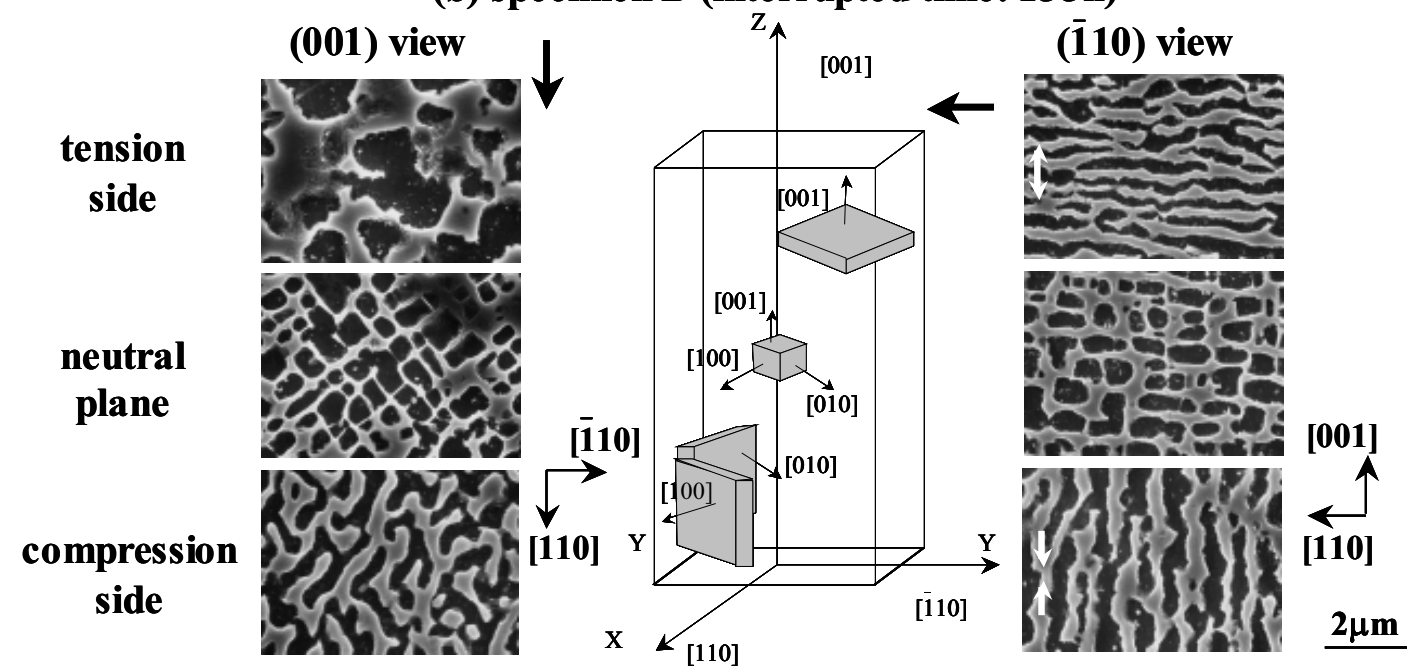

(c) specimen $C$ (interrupted time: $170 \mathrm{~h}$ )

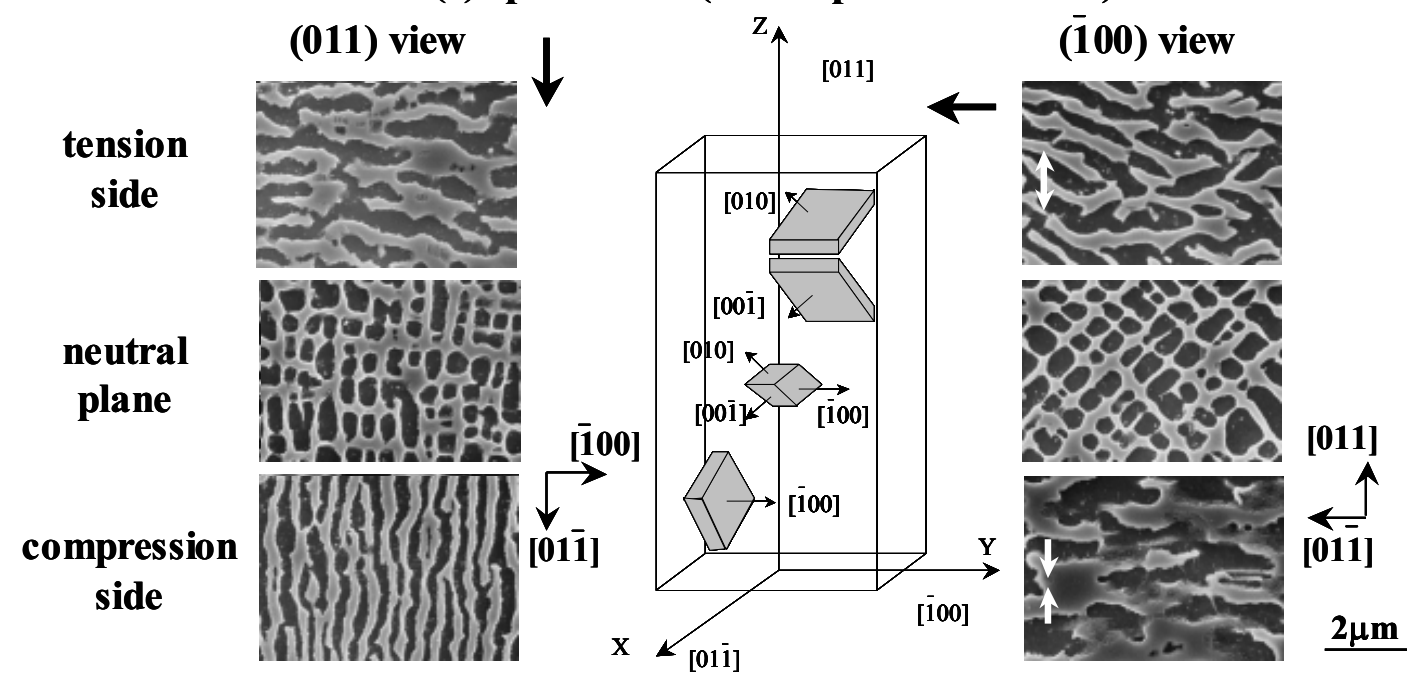

(d) specimen D (interrupted time: $450 \mathrm{~h}$ )

Figure 16 Secondary electron images and corresponding schematic representations of the $\gamma^{\prime}$ morphology after bending creep tests at $982^{\circ} \mathrm{C} / 206 \mathrm{MPa}$ for the four kinds of YH61 specimens with different crystallographic arrangements shown in Figure 5 . The white arrows indicate the stress axis. 
In the case of the specimen D, while its secondary orientation corresponded to the orientation rotated from that of the specimen A by $90^{\circ}$, developed microstructure after the bending creep test also corresponded to the one rotated from that of the specimen $\mathrm{A}$ by $90^{\circ}$ in both the tension and compression sides. This result indicates that the arrangement between the slip system and developed microstructure during creep tests was constant when the secondary orientation was rotated. Therefore, microstructural evolution can be considered to show no influence on the secondary orientation dependence of the deformation in this condition, although no dependence was actually observed.

In the case of specimens $\mathrm{B}$ and $\mathrm{C}$ whose tensile/compressive directions were [001], one type of well-elongated $\gamma$ ' plates, which were normal to [001], were observed in the tension side while two types of plates, which were normal to [100] and [010], respectively, were observed in the compression side. The observed microstructure in the specimen $\mathrm{C}$ corresponded to the one rotated from that in the specimen $\mathrm{B}$ by $90^{\circ}$ as observed in the relationship between the specimens $\mathrm{A}$ and $\mathrm{D}$.

It is very interesting that same type of $\gamma^{\prime}$ plates, which were normal to $\langle 100\rangle$, were observed in the compression side of the [011] specimens and the tension side of the [001] specimens although the plates of the [011] specimens were parallel to the stress axis and those of the [001] specimens were perpendicular to the stress axis. The same observation applies to the two types of $\gamma$ plates. Two same types of $\gamma^{\prime}$ plates, which were elongated to $<100>$, were observed in the tension side of the [011] specimens and the compression side of the [001] specimens although the plates coalesced at an angle of $45^{\circ}$ to the stress axis in the case of [011] specimens and $90^{\circ}$ in the case of [001] specimens.

Tien and Copley [13] showed tensile stress for [011] specimens of Udimet 700 caused $\gamma$ ' bars perpendicular to the stress axis while two types of plates were observed for the tension side in the specimens A and D. A same kind of difference was observed for microstructure of [001] specimens after compressive creep. Compressive stress for [001] specimens of Udimet 700 was reported to cause $\gamma$ ' bars parallel to the stress axis while two types of plates were observed for the compression side in the specimens $\mathrm{B}$ and $\mathrm{C}$. The difference observed for compressive stress of [001] specimens is that $\{100\}$ planes, which were parallel to the stress axis, coalesced or not in addition to the coalescence on $\{100\}$ planes perpendicular to the stress axis. YH61 required the coalescence of the two opposite $\{100\}$ planes parallel to the stress axis in addition to the two $\{100\}$ planes perpendicular to the stress axis; therefore, $\gamma$ ' plates were developed. In the case of Udimet 700 , two $\{100\}$ planes perpendicular to the stress axis were only required to coalesce; therefore, rods parallel to the stress axis were developed. These results indicate that, in the case of YH61, the elastic misfit of $\{100\}$ planes parallel to the stress axis could not be fully relaxed by the compressive strain due to its higher positive lattice misfit (about $0.3 \%$ at room temperature [5]); therefore, $\{100\}$ planes parallel to the stress axis were required to coalesce. On the other hand, in the case of Udimet 700, the elastic misfit of $\{100\}$ planes parallel to the stress axis could be relaxed by the compressive strain due to its lower positive lattice misfit $(0.02 \%$ at room temperature [13]); therefore, $\{100\}$ planes parallel to the stress axis did not need to coalesce. Although more extensive discussion should be required to reveal the correct mechanism which causes the difference of the developed microstructures between YH61 and Udimet 700, the difference of the lattice misfit between both two alloys can be considered as one of possible causes of the difference as discussed above.
Finally, it should be noted that the specimens A and B are the probable orientations in the actual shrouded blades; however, the steady-state creep displacement rate for the specimen B was about 4 times faster than that of the specimen $\mathrm{A}$ at $982^{\circ} \mathrm{C} / 294 \mathrm{MPa}$. This result indicates that secondary orientation control of the SC blades may be important to maximize life of SC blades.

\section{Summary}

Bending deformation behaviors of Ni-based directionally solidified (DS) and single crystal (SC) superalloys were studied.

1. For a DS superalloy, the stress exponents for the steady-state creep displacement rates of the bending creep show the almost same values as those for the steady-state creep strain rates of the tensile creep. Activation energy for the bending creep also corresponds to that for the tensile creep within the temperature range of this study.

2. The bending creep behavior of DS superalloys can be deduced from the simple tensile creep test data, because the correspondence of the deformation mechanism between the bending and the tensile creep was proven.

3. A SC superalloy shows notable secondary orientation dependence of the steady-state creep displacement rates at $750^{\circ} \mathrm{C} / 950 \mathrm{MPa}$. The specimen, whose slip system causes the $45^{\circ}$-shear-type slip, exhibits apparently faster creep displacement rate than the specimen, whose slip system causes the hinge-type deformation, even if their tensile/compressive directions are the same.

4. At $982^{\circ} \mathrm{C} / 294 \mathrm{MPa}$, a SC superalloy shows no significant secondary orientation dependence of the creep displacement rates while [011] specimens exhibits higher creep resistance than [001] specimens. The microstructural observations after bending creep tests provide interesting results that one type of raft-like microstructure observed in the tension side of [011] specimens is also found in the compression side of [001] specimens and another type of raft-like microstructure observed in the compression side of the [011] specimens is also found in the tension side of the [001] specimens.

\section{Acknowledgements}

One of the authors would like to acknowledge Dr. Katsumi Iijma for his helpful discussions. Also, one of the authors would like to acknowledge Mr. Mitsuru Kawamatsu of Tokyo Koki Seizousho, Ltd. for his contribution to design of the bending device. Mr. Hideki Fujita performed the SEM analysis and this is gratefully recognized. 


\section{References}

1. J-Y. Buffiere, M. Veron, M. Ignat and M. Dupeux, "Microstructural Changes in a Nickel Based Superalloy Single Crystal Submitted to Bending Creep Tests at High Temperature", Strength of Materials, ed. Oikawa et al., (Japan: The Japan Institute of Metals, 1994), 693-696.

2. M. Ignat, J-Y. Buffiere and J.M. Chaix, "Microstructures Induced by a Stress Gradient in a Nickel-based Superalloys", Acta metal. mater., 41 (1993), 855-862.

3. R. Seleski, "Gas Turbine Efficiency Improvements through Shroud Modifications", http://www.powermfg.com/images/gas-turbine-efficiencyshroud-modifications.pdf.

4. G.M. McColvin, J. Sutton, M. Whitehurst, D.G. Fleck, T.A. Van Vranken, K.Harris, G.L. Erickson and J.B. Wahl, "Application of the Second Generation DS Superalloy CM186LC $^{\circledR}$ to First Stage Turbine Blading in EGT Industrial Gas Turbines", Advances in Turbine Materials, Design and Manufacturing, ed. A. Strang et al., (London, UK: The Institute of Materials, 1997), 339-357.

5. H. Tamaki, A. Yoshinari, A. Okayama and S. Nakamura, K. Kageyama, K. Sato and T. Ohno, "Development of A Low Angle Grain Boundary Resistant Single Crystal Superalloy YH61", Superalloys 2000, ed. T.M. Pollock et al., (Warrendale, PA: TMS, 2000), 757-766.

6. T-Z. Chuang, "Estimation of Power-law creep parameters from bend test data", J. Mater. Sci., 21 (1986), 165-175.

7. G.A. Webster and B.J. Piearcey, "An Interpretation of the Effects of Stress and Temperature on the Creep Properties of a Nickel-Base Superalloy”, Metal. Sci. J., 1 (1967), 97-104.

8. G.R. Leverant and B.H. Kear, "The Mechanism of Creep in Gamma Prime Precipitation-Hardened Nickel-Base Alloys at Intermediate Temperatures”, Metall. Trans., 1 (1970), 491.

9. T.M. Pollock and A.S. Argon, "Creep Resistance of CMSX3 Nickel Base Superalloy Single Crystals", Acta metal., 40 (1992), 1-30.

10. K. Kakehi, "Effect of Plastic Anisotropy on the Creep Strength of Single Crystal of a Nickel-Based Superalloy", Metall. Trans. A., 31A (2000), 421-430.

11. K. Kakehi, "Effect of Plastic Anisotropy on Tensile Strength of Single Crystals of Ni-based Superalloy", Scripta mater., 42 (2000), 197-202.

12. D.M. Shah and A. Cetel, "Creep anisotropy in Nickel base $\gamma$, $\gamma^{\prime}$ and $\gamma / \gamma$ ' superalloy single crystals", Superalloys 1996, ed. R.D. Kissinger et al., (Warrendale, PA: TMS, 1996), 273282.

13. J.K. Tien and S.M. Copley, "The Effect of Orientation and Sense of Applied Uniaxial Stress on the Morphology of Coherent Gamma Prime Precipitates in Stress Annealed Nickel-Base Superalloy Crystals", Metall. Trans., 2 (1971), 543-553. 